\title{
Association of CYP2A6 gene deletion with cancers in Japanese elderly: an autopsy study
}

Maidina Abudushataer ${ }^{1}$, Noriko Sato ${ }^{1}$, Makiko Mieno $^{2}$, Motoji Sawabe $^{3}$, Masaaki Muramatsu $^{1^{*}}$ (D) and Tomio Arai ${ }^{4}$

\begin{abstract}
Background: CYP2A6 is an enzyme involved in oxidation of a number of environmental chemicals, including nicotine, pro-carcinogenic nitrosamines and polycyclic aromatic hydrocarbons (PAHs). The whole gene deletion of CYP2A6 (CYP2A6*4) is prevalent in East Asian population. Whether or not CYP2A6*4 associates with cancer is still controversial.

Methods: We undertook an association study to determine whether deletion of CYP2A6 gene associates with total cancer and major cancer types employing data of consecutive autopsy cases registered in the Japanese singlenucleotide polymorphisms for geriatric research (JG-SNP) database. The presence of cancer were inspected at the time of autopsy and pathologically confirmed. Genotyping for CYP2A6 wild type (W) and deletion (D) was done by allele specific RT-PCR method.
\end{abstract}

Results: Among 1373 subjects, 826 subjects (60.2\%) were cancer positive and 547 subjects (39.8\%) were cancer negative. The genotype frequency in the whole study group for WW, WD and DD were 65.0, 30.6 and 4.4\%, respectively, which obeyed the Hardy-Weinberg equilibrium $(p=0.20)$. Total cancer presence, as well as major cancers including gastric, lung, colorectal, and blood cancers did not show any positive association with CYP2A6 deletion. When male and female were separately analyzed, CYP2A6 deletion associated with decreased gastric cancer risk in female ( $\mathrm{OR}=0.49,95 \% \mathrm{Cl}: 0.25-0.95, p=0.021$, after adjustment for age, smoking and drinking). When smoker and non-smoker were separately analyzed, CYP2A6 deletion associated with decreased total cancer in female nonsmokers ( $\mathrm{OR}=0.67,95 \% \mathrm{Cl}: 0.45-0.99, p=0.041$ after adjustment). On the other hand, CYP2A6 deletion associated increase blood cancers in smokers ( $\mathrm{OR}=2.05,95 \% \mathrm{Cl}: 1.19-3.53, p=0.01$ after adjustment).

Conclusion: The CYP2A6 deletion may not grossly affect total cancer. It may associate with individual cancers in sex and smoking dependent manner. Further studies with larger sample size are warranted to confirm our results.

Keywords: CYP2A6*1, CYP2A6*4, Pathology, Cancer, Smoking

\footnotetext{
* Correspondence: muramatsu.epi@mri.tmd.ac.jp

'Department of Molecular Epidemiology, Medical Research Institute, Tokyo Medical and Dental University, Tokyo, Japan

Full list of author information is available at the end of the article
}

(c) The Author(s). 2020 Open Access This article is licensed under a Creative Commons Attribution 4.0 International License, which permits use, sharing, adaptation, distribution and reproduction in any medium or format, as long as you give appropriate credit to the original author(s) and the source, provide a link to the Creative Commons licence, and indicate if changes were made. The images or other third party material in this article are included in the article's Creative Commons licence, unless indicated otherwise in a credit line to the material. If material is not included in the article's Creative Commons licence and your intended use is not permitted by statutory regulation or exceeds the permitted use, you will need to obtain permission directly from the copyright holder. To view a copy of this licence, visit http://creativecommons.org/licenses/by/4.0/. The Creative Commons Public Domain Dedication waiver (http://creativecommons.org/publicdomain/zero/1.0/) applies to the data made available in this article, unless otherwise stated in a credit line to the data. 


\section{Background}

Cytochrome P450 2A6 (CYP2A6) is known as a pharmacogene, primarily expressed in the liver, and catalyzes several clinically used drugs, including tegafur, letrozole, caffeine and other substrates $[1,2]$. CYP2A6 plays a major role in the nicotine metabolic pathway. It catalyzes nicotine to inactive metabolic cotinine, followed by further metabolism of cotinine to trans-3'-hydroxycotinine (3HC) $[2,3]$. CYP2A6 is also responsible for the metabolic activation of tobacco-specific pro-carcinogens such as 4-(methylnitrosamino)-1-(3-pyridyl)-1-butanone (NNK) and 4-(methylnitrosamino)- 1-(3-pyridyl)-1-butanol (NNAL), which are found in the cigarette smoke [4 ,5]. Recently, CYP2A6 enzyme has been shown to metabolize not only tobacco-related nitrosamines but also polycyclic aromatic hydrocarbons (PAHs) and aryland heterocyclic amines [6].

CYP2A6 gene is highly polymorphic, with more than 40 variants identified to date [7]. Genetic variations of CYP2A6 gene have been widely studied with respect to its association with levels of nicotine metabolites in vivo, nicotine dependence, smoking behavior and cancer susceptibility. The allele frequencies of CYP2A6 genetic variants differ by racial/ethnic groups. Wild type allele CYP2A6* 1 is considered as a wild type reference allele. In comparison, the whole gene deletion allele CYP2A6*4 is one of the most common variants in Asian ancestry, with MAF of $20 \sim 24 \%$ in Japanese $[8,9,10,11]$. The CYP2A6 deletion has been studied with respect to various tobaccorelated cancers, but there remain inconsistent results. To this end, we employed consecutive autopsy cases of Japanese elderly registered in the JG-SNP database to determine the association between CYP2A6 deletion and risk of total cancer and major cancer types. This was thought to be important since recent haplotype analysis of CYP2A6 gene revealed that CYP2A6*4 cannot be tagged by nearby SNPs $\left(\mathrm{r}^{2}<0.4\right)[12]$.

\section{Methods}

\section{Subjects}

The study population was obtained from Internet database of Japanese single-nucleotide polymorphisms (SNPs) for geriatric research (JG-SNP) [13]. Briefly, JG-SNP database consists of consecutive autopsy cases performed at the Tokyo Metropolitan Geriatric Hospital between 1995 and 2006. Pathological diagnosis was made by MS and TA. Clinical information including subject age, gender, smoking and drinking history was obtained from medical chart. Informed consent for the use of autopsy samples and patient clinical data for this study was obtained from the family of study participants at the time of autopsy. The definition of the drinkers/smokers were defined by current drinkers/smokers and ever drinkers/smokers. Never drinkers/smokers were those who never drink/smoke.
Clinical data such as drinking and smoking habit were extracted from patient medical records. The study protocol was approved by the Ethics Committees of Tokyo Geriatric Hospital and Tokyo Medical and Dental University and authorized by TMDU Research Ethics Committee under the number 2016-011-02.

The genomic DNA was isolated from kidney cortex by phenol-chloroform method and stored at $-20^{\circ} \mathrm{C}$ until use. Concentration of DNA samples was determined by optical density of 260/280. We used 1373 subjects of which the DNA samples were present.

\section{Primer/probe design and reaction mixture}

The primer and probe sets were designed to detect the presence and absence of CYP2A6 gene as previously described by Yamazaki et al. [14]. The sequence of primers and probes are shown in Table 1 . The reaction was performed in a $10 \mu \mathrm{L}$ volume with $10 \mathrm{ng}$ genomic DNA. The reaction mixture contained $0.75 \mu \mathrm{M}$ CYP2A6_ex2_3_F, $1.0 \mu \mathrm{M}$ CYP2A7_ex9_F, $0.25 \mu \mathrm{M}$ CYP2A6_ex2_3_R, $0.25 \mu \mathrm{M}$ CYP2A6_3UTR_R, $0.25 \mu \mathrm{M}$ CYP2A6_ex2_3_ probe, 0.4 $\mu$ M CYP2A6_4_probe and TaqMan GTXpress ${ }^{\text {TM }}$ Master Mix (Applied Biosystems). CYP2A6_ex2_3_probe was labeled with hexachloro-fluorescein (HEX) for detecting CYP2A6 wild-type, and CYP2A6_4_probe was labeled with 6-fluorescein amidite (FAM) for detecting CYP2A6 whole-gene deletion.

\section{Quantitative real-time PCR}

The genotyping for the CYP2A6 gene was done by using multiplex real-time polymerase chain reaction (RT-PCR) method with the above dual-labeled probes. The genomic DNAs were placed into 384 well plates, and were dried down. Mixture of above reagent was added to each well, centrifuged briefly, then sealed by foil and the PCR reaction was run on Light Cycler ${ }^{\circledR} 480$ I 384 (Roche, Penzberg, Germany). The thermal cycler conditions were initiated at $95^{\circ} \mathrm{C}$ for $20 \mathrm{~s}$ followed by 40 cycles of

Table 1 Primer and probe sets for detecting CYP2A6*1 and *4 allele

\begin{tabular}{|c|c|c|}
\hline & Primers and probes & Target Sequence \\
\hline \multirow[t]{3}{*}{ CYP2A6*1 } & $\begin{array}{l}\text { Forward Primer } \\
\text { (CYP2A6_ex2_3_F) }\end{array}$ & 5'-AGCTCTGCTGGGCAA-3' \\
\hline & $\begin{array}{l}\text { Reverse Primer } \\
\text { (CYP2A6_ex2_3_R) }\end{array}$ & 5'-CCCCTGCTCACCGCCA-3' \\
\hline & $\begin{array}{l}\text { Probe } \\
\text { (CYP2A6_ex2_3_probe) }\end{array}$ & $\begin{array}{l}\text { 5'-TGTCTCCATTCCCGCGTTCA- } \\
\text { 3'(HEX) }\end{array}$ \\
\hline \multirow[t]{3}{*}{ CYP2A6*4 } & $\begin{array}{l}\text { Forward Primer } \\
\text { (CYP2A7_ex9_F) }\end{array}$ & 5'-TCCCCCAAACACGTGGT-3' \\
\hline & $\begin{array}{l}\text { Reverse Primer } \\
\text { (CYP2A6_3UTR_R) }\end{array}$ & 5'-AGGTGAGCGTGCAATG-3' \\
\hline & $\begin{array}{l}\text { Probe } \\
\text { (CYP2A6_4_probe) }\end{array}$ & $\begin{array}{l}\text { 5'-AGAGGGAAGAGAAGAAACAGAA- } \\
3^{\prime}(\text { FAM) }\end{array}$ \\
\hline
\end{tabular}


denaturation at $95^{\circ} \mathrm{C}$ for $20 \mathrm{~s}$, annealing at $60^{\circ} \mathrm{C}$ for $30 \mathrm{~s}$ and extension at $72{ }^{\circ} \mathrm{C}$ for $31 \mathrm{~s}$. The genotype was determined from RT-PCR fluorescent curve by optical observation.

\section{Statistical analysis}

Hardy-Weinberg Equilibrium (HWE) for CYP2A6 genotypes was determined using Chi-Square test. Chi- Square or Fisher's exact tests were used to compare CYP2A6 genotypes and cancer or behavior habits of smoking and drinking. Adjustments were done for age, sex, smoking and drinking status where appropriate. Binominal logistic regression was used to calculate the odds ratio (OR), 95\% confidence-intervals $(\mathrm{CI})$ and the $\mathrm{p}$-values to estimate the relationship. All p-values are reported two-sided, and < 0.05 were considered to be statistically significant. Subgroup analyses based on gender and smoking status were also performed. Adjustment for multiple testing, such as Bonferroni correction, was not applied for its conservative nature. Statistical analysis was performed using the IBM SPSS Statistics software 25.0 (IBM; New York, USA).

\section{Results}

Characteristics of the study subjects

Selected demographic variables, including the sites of cancers, and risk factors are shown in Table 2. The study included 1373 samples, including 743 men and 630 women. The mean age of subjects was $80.1 \pm 9.0$ years. The subjects consist of 655 smokers and 633 non-smokers with 85 missing data. Alcohol drinking data include 456 drinkers and 833 non-drinkers and 84 missing data. Among all samples, 826 patients were diagnosed as having at least one cancer (60.2\%), while others were cancer negative $(n=547,39.8 \%)$. The major cancer includes gastric cancer $(n=163,11.9 \%)$, colorectal cancer $(n=130,9.5 \%)$, lung cancer $(n=128$, 9.3\%), and blood cancer $(n=127,9.3 \%)$. In this study, we evaluated these high prevalent cancers.

\section{Genotyping and allele frequency of CYP2A6}

A typical reaction curves are shown in Fig. 1. Based on the obtained amplification curves of HEX and FAM fluorescence, genotypes of CYP2A6 wild type homozygotes, heterozygotes and deletion homozygotes were

Table 2 Distribution of selected demographic variables and risk factors

\begin{tabular}{|c|c|c|c|c|}
\hline & All subjects $(n=1373)$ & Cancer-free $(n=547)$ & Cancer-bearing $(n=826)$ & $p$-value ${ }^{*}$ \\
\hline Age at death, yearst & $80.1 \pm 9.0$ & & & \\
\hline$\geq 80, \mathrm{n}(\%)$ & $729(53)$ & $300(55)$ & $429(52)$ & \\
\hline$<80$ & $644(47)$ & $247(45)$ & $397(48)$ & 0.2946 \\
\hline \multicolumn{5}{|l|}{ Gender, n (\%) } \\
\hline Male & $743(54)$ & $273(50)$ & $470(57)$ & \\
\hline Female & $630(46)$ & $274(50)$ & $356(43)$ & 0.0128 \\
\hline \multicolumn{5}{|l|}{ Smoking, n (\%) } \\
\hline Non-smoker & $633(46)$ & $256(47)$ & $377(45)$ & \\
\hline Smoker & $655(48)$ & $245(45)$ & $410(50)$ & 0.2776 \\
\hline Missing & $85(6)$ & $46(8)$ & $39(5)$ & \\
\hline \multicolumn{5}{|l|}{ Alcohol, n (\%) } \\
\hline Non-drinker & $833(61)$ & $346(63)$ & $487(59)$ & \\
\hline Drinker & $456(33)$ & $157(29)$ & $299(36)$ & 0.0143 \\
\hline Missing & $84(6)$ & $44(8)$ & $40(5)$ & \\
\hline \multicolumn{5}{|l|}{ Cancer, n (\%) } \\
\hline 0 & & & $547(40)$ & \\
\hline 1 & & & $604(44)$ & \\
\hline 2 & & & $178(13)$ & \\
\hline$\geq 3$ & & & $44(3)$ & \\
\hline \multicolumn{5}{|l|}{ Cancer sites, n (\%) } \\
\hline Gastric cancer & & & $163(12)$ & \\
\hline colorectal cancer & & & $130(10)$ & \\
\hline Lung cancer & & & $128(9)$ & \\
\hline Blood cancer & & & $127(9)$ & \\
\hline
\end{tabular}

${ }^{\dagger}$ means \pm SDs

* $\mathrm{p}$-value for Fisher's exact probability test 


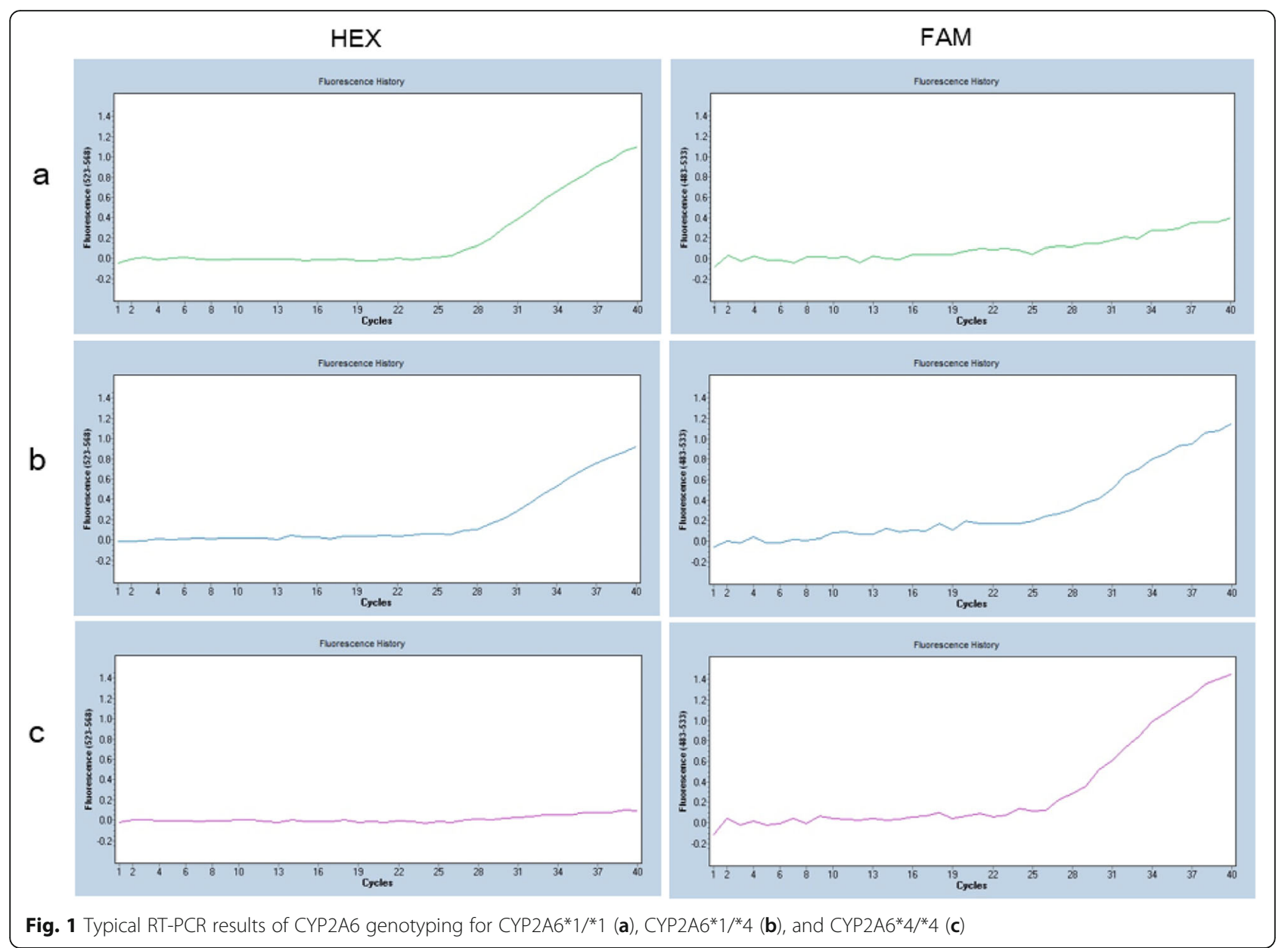

determined. The presence of CYP2A6 (W) showed HEX fluorescence but did not show FAM fluorescence (Fig. 1.a). The heterozygote CYP2A6 W and deletion (D) showed both fluorescences (Fig. 1.b). Whole-gene deletion type CYP2A6 (D) showed FAM fluorescence but did not show HEX fluorescence (Fig. 1.c). Among all samples, 892 subjects were determined as W/W (65.0\%), 420 samples were determined as W/D (30.6\%) and 61 samples were determined as D/D (4.4\%). The allele frequencies of CYP2A6 W and D alleles were 80.2 and $19.8 \%$, respectively. The whole study group obeyed the HWE $(p=0.20)$, and the allele frequency was consistent with previous studies in the Japanese population $[8,9,10,11]$.

\section{Association of CYP2A6 genotype with cancer}

First, association of CYP2A6 W/D genotype and total cancer were determined for all subjects (Table 3). We studied the association of CYP2A6 (D) and total cancer in different models of dominant (DD + WD: WW), recessive (DD: WD + WW) and additive (WW: WD: DD). In any of the genetic models, no association was found in crude analysis and after adjusted for age, gender, smoking and drinking. The genotype distribution obeyed
HWE in cancer-free group ( $p=0.57)$, but slightly deviated in cancer-bearing group $(p=0.03)$. Association for independent cancer of gastric, colorectal, lung and blood were also studied and no associations were found.

Next, we separately analyzed male and female (Table 4). In male, association of CYP2A6 W/D genotypes gave no association for total cancer, and independent cancers in crude analysis and adjusted for age, smoking and drinking.

Table 3 Genetic models for total cancer

\begin{tabular}{|c|c|c|c|c|c|c|}
\hline \multirow[t]{3}{*}{ Dominant } & \multirow{3}{*}{$\begin{array}{l}- \\
+\end{array}$} & WW (\%) & \multicolumn{2}{|c|}{ WD + DD (\%) } & \multirow{3}{*}{$\begin{array}{l}p \text {-value } \\
0.153\end{array}$} & \multirow{3}{*}{$\begin{array}{l}p \text {-value } \text {. }^{* *} \\
0.132\end{array}$} \\
\hline & & $343(63)$ & 204(37) & & & \\
\hline & & $549(66)$ & $277(34)$ & & & \\
\hline \multirow[t]{3}{*}{ Recessive } & & $W W+W D$ & (\%) & DD (\%) & & \\
\hline & - & $526(96)$ & & $21(4)$ & 0.377 & 0.539 \\
\hline & + & $786(95)$ & & $40(5)$ & & \\
\hline \multirow[t]{3}{*}{ Additive } & & WW (\%) & WD (\%) & DD (\%) & & \\
\hline & - & $343(63)$ & 183(33) & $21(4)$ & 0.142 & \\
\hline & + & $549(66)$ & 237(29) & $40(5)$ & & \\
\hline
\end{tabular}

$W W$ wild-type (reference); $W D$ heterozygote; $D D$ whole-gene deletion;-(cancerfree); + (cancer-bearing)

*p-value was done by Crude analysis

** Logistic regression analysis adjusted by age, gender, smoking and drinking 


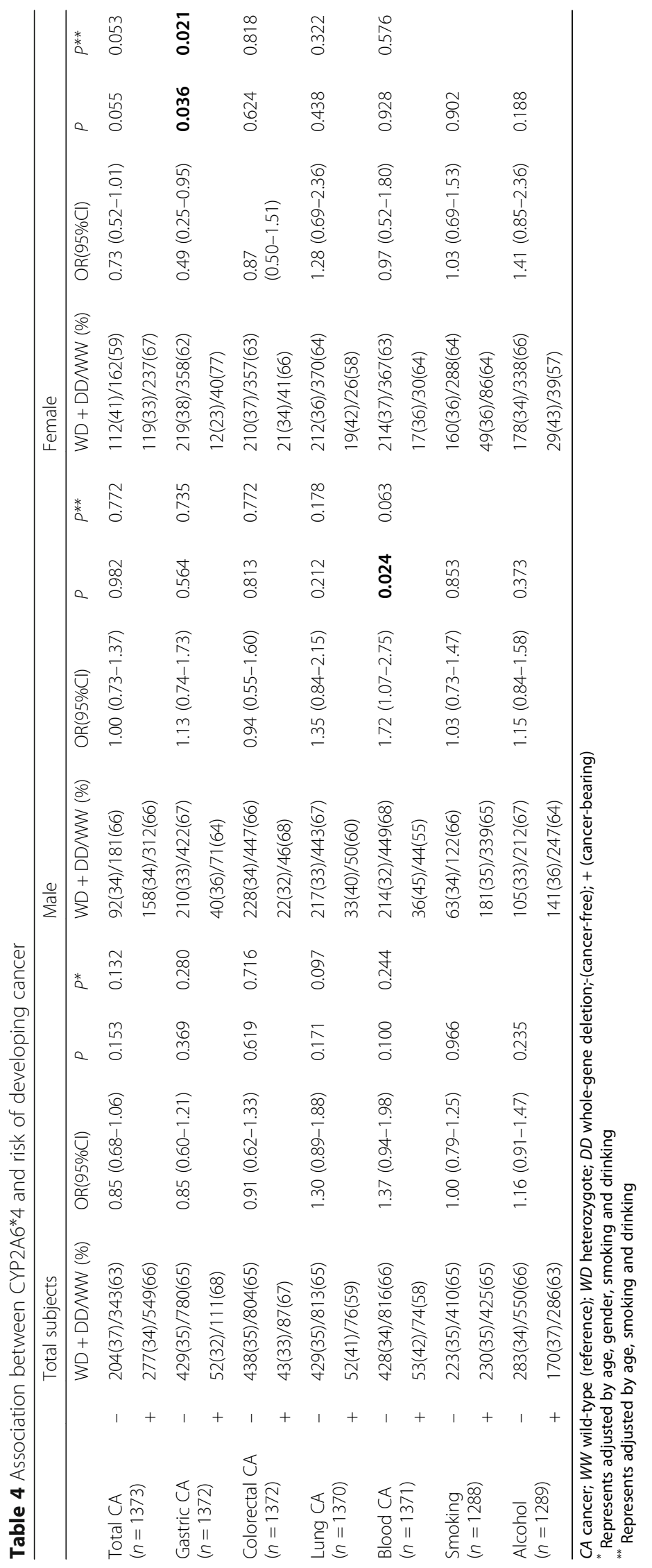


As for blood cancer there was a positive sign of association (WD + DD/WW, OR = 1.72, 95\%CI: 1.07 2.75, $p=$ 0.024 ) in crude analysis, which did not remain positive after adjustment $(p=0.063)$.

In female, CYP2A6 deletion barely did not reach significant level with total cancer in crude analysis $(p=$ 0.055). With respect to colorectal cancer, lung cancer and blood cancer in female, there was no significant association related with CYP2A6 deletion in crude and adjusted analysis. Only, CYP2A6 deletion significantly associated with decreased risk of gastric cancer presence in crude analysis $(p=0.036)$, and remained positive after adjustment $(p=0.021)$. We also determined whether CYP2A6 deletion associates with smoking and drinking habits. As shown in the last two rows of Table 4, these health behaviors were not affected by CYP2A6 deletion.

We further analyzed smoker and nonsmoker (Supplementary Table 1 and 2). As for smoker, CYP2A6 deletion did not associate with total cancer, nor independent cancers of gastric, colorectal and lung. However, there was a positive sign with increased blood cancer in smokers (OR $=2.05$, 95\%CI: 1.19 3.53, $p=0.01$, after adjustment). As for non-smokers, total cancer was barely non-significant $(\mathrm{OR}=0.73,95 \% \mathrm{CI}$ : $0.53-1.02 p=0.08$, after adjustment) and also non-significant for independent cancers. Only in female nonsmokers, CYP2A6 deletion associated with decreased total cancer $(\mathrm{OR}=0.67$, 95\%CI: 0.45-0.99, $p=0.041$ after adjustment).

\section{Discussion}

In this study, we determined the association of CYP2A6 gene deletion genotypes with various cancer risks. Overall, our findings suggested that CYP2A6 deletion do not largely affect presence of total cancer. However, there were some positive signs that CYP2A6 deletion might associate with the presence of independent cancer in sex and smoking dependent manner.

CYP2A6 variation has been recurrently studied for smoking behavior. In general, reduced function of polymorphic CYP2A6 enzyme, including gene deletion has been associated with decreased smoking behaviors [2, 12]. However, our study did not find any association between CYP2A6 deletion and smoking habit (Table 4). This may be due to binominal nature of smoking habits in our database.

CYP2A6 variants have been studied for tobaccorelated cancers such as lung $[15,16,17,18,19,20,21]$, bladder [22, 23], esophageal [24], oral [25] and urothelial [26] cancers. Since many cancers are tobacco related, we first studied whether CYP2A6 deletion associate with total cancer in our study sample. We could not find any association for total cancer in dominant, recessive and additive genetic models (Table 3 ).
We then studied independent cancers of lung, colorectal, gastric, and blood cancers, employing dominant model to detect the association (Table 4). Our results did not find any association between CYP2A6 deletion with any of these cancers. The most studied cancer in the literature is lung cancer and decreased function of CYP2A6 generally associated with lower lung cancer risk $[15,16,17,18,19,20,21]$ '. The reason why we could not detect CYP2A6 deletion and lung cancer may be due to small sample size and that we did not consider other low active variants (see the limitation below).

Our study found a significant association between CYP2A6 deletion with decreased risk of gastric cancer in Japanese female. Also CYP2A6 deletion associated with decreased total cancer in non-smoking female. Since CYP2A6 activates not only tobacco-related nitrosamines, but also activate number of environmental chemicals such as polycyclic aromatic hydrocarbons (PAHs) and aryl- and heterocyclic amines, CYP2A6 deletion may have a lower activity to convert them into active carcinogens in vivo.

Intriguingly, CYP2A6 deletion associated with increased blood cancer only in smokers $(\mathrm{OR}=2.05$, 95\%CI: 1.19 3.53, $p=0.01$, after adjustment). This result is tempting to speculate that the blood cancers might be caused by a different spectrum of carcinogens, which are inactivated by CYP2A6. However, this notion should be considered a working hypothesis and these observations must be replicated in a larger sample size study. Indeed, one Japanese study employing 120 gastric cancer patients and 158 controls has shown that CYP2A6 deletion homozygotes increase gastric cancer risk [27], which appears to be contradictory to our results.

There are limitations in our study. First, this was a hospital-based autopsy study and we had limited access to clinical information on lifestyle variables that could impact the development of cancer. Second, the autopsies were performed on many of the deaths (40\%) that occurred in the hospital, and the causes of death among our autopsy cases were similar to those reported in a national survey, we cannot rule out the possibility of selection bias. Such bias can arise from chance of admission, consent to autopsy, cause of death, and autopsy practice. Survival bias is also a possibility, as particular genotypes may be associated with other diseases or influence the lifespan of certain subjects, thereby introducing bias into the study population. Third, the current assay did not discriminate CYP2A6*1 from CYP2A6*7 and *9 which appear to have low activity scores [21]. However, CYP2A6 *4 is the whole gene deletion and expected to have the most extreme phenotype and cannot be tagged by nearby SNPs $\left(\mathrm{r}^{2}<0.4\right)[12]$.

\section{Conclusion}

CYP2A6 deletion may not largely affect presence of total cancer. CYP2A6 deletion may associate with decreased 
gastric cancer in female and decreased total cancer in nonsmoking female. These results warrant further confirmation with larger sample size studies.

\section{Supplementary information}

Supplementary information accompanies this paper at https://doi.org/10. 1186/s12885-020-6663-4

Additional file 1. Supplementary Table 1. Association between CYP2A6*4 and risk of developing cancer with dominant model for smokers.

Additional file 2. Supplementary Table 2. Association between CYP2A6*4 and risk of developing cancer with dominant model for nonsmokers.

\begin{abstract}
Abbreviations
3HC: Trans-3'-hydroxycotinine; CYP2A6: Cytochrome P450 2A6; FAM: 6fluorescein amidite; HEX: Hexachloro-fluorescein; HWE: Hardy-Weinberg Equilibrium; JG-SNP: Japanese single-nucleotide polymorphisms for geriatric research; NNAL: 4-(methylnitrosamino)- 1-(3-pyridyl)-1-butanol; NNK: 4(methylnitrosamino)-1-(3-pyridyl)-1-butanone; PAHs: Polycyclic aromatic hydrocarbons; RT-PCR: real-time polymerase chain reaction; SNPs: Singlenucleotide polymorphisms
\end{abstract}

\section{Acknowledgements}

Not applicable.

\section{Authors' contributions}

The study was designed by MMu. Pathological analysis was performed by MS and TA. Clinical data acquisition and analysis were performed by MMi. Genotyping and statistical analyses were performed by MA and NS. The manuscript was written by MA and MMu. All authors read and approved the manuscript.

\section{Funding}

This study was funded by grant no.17 K09081 from MEXT/JSPS, and the Kyoten Program of the Medical Research Institute, TMDU. The funding bodies had no role in the design of the study, the collection, analysis, or interpretation of data or in writing the manuscript.

\section{Availability of data and materials}

All datasets used or analysed for this study are available from the corresponding author upon reasonable request.

\section{Ethics approval and consent to participate}

Written informed consent was obtained from the bereaved families of the patients at the time of autopsy. The study protocol was approved by the Ethics Committees of Tokyo Geriatric Hospital and Tokyo Medical and Dental University and authorized by TMDU Research Ethics Committee under the number 2016-011-02.

\section{Consent for publication}

Not applicable.

\section{Competing interests}

The authors declare there are no competing interests.

\section{Author details}

'Department of Molecular Epidemiology, Medical Research Institute, Tokyo Medical and Dental University, Tokyo, Japan. ${ }^{2}$ Center for Information, Jichi Medical University, Tochigi, Japan. ${ }^{3}$ Department of Molecular Pathology, Graduate School of Medical and Dental Sciences, Tokyo Medical and Dental University, Tokyo, Japan. ${ }^{4}$ Department of Pathology, Tokyo Metropolitan Geriatric Hospital, Tokyo, Japan.
Received: 30 August 2019 Accepted: 20 February 2020

Published online: 04 March 2020

\section{References}

1. McDonagh EM, Wassenaar C, David SP, Tyndale RF, Altman RB, Whirl-Carrillo $M$, Klein TE. PharmGKB summary - very important Pharmacogene information for cytochrome P-450, family 2, subfamily a, polypeptide 6 . Pharmacogenet Genomics. 2012;22(9):695-708.

2. Tanner JA, Tyndale RF. Variation in CYP2A6 activity and personalized medicine. J Pers Med. 2017;7(4):pii: E18.

3. Murphy SE. Nicotine metabolism and smoking: ethnic differences in the role of P450 2A6. Chem Res Toxicol. 2017;30(1):410-9.

4. Zhu AZ, Binnington MJ, Renner CC, Lanier AP, Hatsukami DK, Stepanov I, Watson CH, Sosnoff CS, Benowitz NL, Tyndale RF. Alaska native smokers and smokeless tobacco users with slower CYP2A6 activity have lower tobacco consumption, lower tobacco-specific nitrosamine exposure and lower tobacco-specific nitrosamine bioactivation. Carcinogenesis. 2013;34(1):93-101.

5. Yuan JM, Nelson HH, Carmella SG, Wang R, Kuriger-Laber J, Jin A, AdamsHaduch J, Hecht SS, Koh WP, Murphy SE. CYP2A6 genetic polymorphisms and biomarkers of tobacco smoke constituents in relation to risk of lung cancer in the Singapore Chinese health study. Carcinogenesis. 2017;38:411-8.

6. Shimada T, Murayama N, Yamazaki H, Tanaka K, Takenaka S, Komori M, Kim D, Guengerich FP. Metabolic activation of polycyclic aromatic hydrocarbons and aryl and heterocyclic amines by human cytochromes P450 2A13 and 2A6. Chem Res Toxicol. 2013:26(4):529-37.

7. Zhou Y, Ingelman-Sundberg M, Lauschke VM. Worldwide Distribution of Cytochrome P450 Alleles: A meta-analysis of population-scale sequencing projects. Clin Pharmacol Ther. 2017;2(4):688-700.

8. Nakajima M, Kwon JT, Tanaka N, Zenta T, Yamamoto Y, Yamamoto H, Yamazaki H, Yamamoto T, Kuroiwa Y, Yokoi T. Relationship between inter individual differences in nicotine metabolism and CYP2A6 genetic polymorphism in humans. Clin Pharmacol Ther. 2001;69(1):72-8.

9. Raunio H, Rautio A, Gullstén H, Pelkonen O. Polymorphisms of CYP2A6 and its practical consequences. Br J Clin Pharmacol. 2001:52(4):357-63.

10. Nakajima M, Fukami T, Yamanaka H, Higashi E, Sakai H, Yoshida R, Kwon JT, McLeod HL, Yokoi T. Comprehensive evaluation of variability in nicotine metabolism and CYP2A6 polymorphic alleles in four ethnic populations. Clin Pharmacol Ther. 2006:80(3):282-97.

11. Schoedel KA, Hoffmann EB, Rao Y, Sellers EM, Tyndale RF. Ethnic variation in CYP2A6 and association of genetically slow nicotine metabolism and smoking in adult Caucasians. Pharmacogenetics. 2004;14(9):615-26.

12. Kumasaka N, Aoki M, Okada Y, Takahashi A, Ozaki K, Mushiroda T, Hirota T, Tamari M, Tanaka T, Nakamura Y, Kamatani N, Kubo M. Haplotypes with copy number and single nucleotide polymorphisms in CYP2A6 locus are associated with smoking quantity in a Japanese population. PLoS One. 2012:7(9):e44507.

13. Sawabe M, Arai T, Kasahara I, Esaki Y, Nakahara K, Hosoi T, Orimo H, Takubo K, Murayama S. Tanaka N; Tokyo metropolitan geriatric medical center; Japan Science and Technology Agency. Developments of geriatric autopsy database and internet-based database of Japanese single nucleotide polymorphisms for geriatric research (JG-SNP). Mech Ageing Dev. 2004; 125(8):547-52.

14. Shimizu M, Sawaya R, Kishimoto I, Yamazaki H. Genotyping of wild-type cytochrome P450 2A6 and whole-gene deletion using human blood samples and a multiplex real-time polymerase chain reaction method with dual-labeled probes. Clin Chim Acta. 2015;441:71-4.

15. Wassenaar CA, Ye Y, Cai Q, Aldrich MC, Knight J, Spitz MR, Wu X, Blot WJ, Tyndale RF. CYP2A6 reduced activity gene variants confer reduction in lung cancer risk in African American smokers-findings from two independent populations. Carcinogenesis. 2015;36(1):99-103.

16. Park SL, Tiirikainen MI, Patel YM, Wilkens LR, Stram DO, Le Marchand L, Murphy SE. Genetic determinants of CYP2A6 activity across racial/ethnic groups with different risks of lung cancer and effect on their smoking intensity. Carcinogenesis. 2016;37(3):269-79.

17. Yuan JM, Nelson HH, Butler LM, Carmella SG, Wang R, Kuriger-Laber JK, Adams-Haduch J, Hecht SS, Gao YT, Murphy SE. Genetic determinants of cytochrome P450 2A6 activity and biomarkers of tobacco smoke exposure in relation to risk of lung cancer development in the Shanghai cohort study. Int J Cancer. 2016;138(9):2161-71. 
18. Ariyoshi N, Miyamoto M, Umetsu Y, Kunitoh H, Dosaka-Akita H, Sawamura Y, Yokota J, Nemoto N, Sato K, Kamataki T. Genetic polymorphism of CYP2A6 gene and tobacco-induced lung cancer risk in male smokers. Cancer Epidemiol Biomark Prev. 2002;11(9):890-4.

19. Fujieda M, Yamazaki H, Saito T, Kiyotani K, Gyamfi MA, Sakurai M, DosakaAkita H, Sawamura Y, Yokota J, Kunitoh H, Kamataki T. Evaluation of CYP2A6 genetic polymorphisms as determinants of smoking behavior and tobaccorelated lung cancer risk in male Japanese smokers. Carcinogenesis. 2004; 25(12):2451-8.

20. Tamaki Y, Arai T, Sugimura H, Sasaki T, Honda M, Muroi Y, Matsubara Y, Kanno S, Ishikawa M, Hirasawa N, Hiratsuka M. Association between cancer risk and drug-metabolizing enzyme gene (CYP2A6, CYP2A13, CYP4B1, SULT1A1, GSTM1, and GSTT1) polymorphisms in cases of lung cancer in Japan. Drug Metab Pharmacokinet. 2011;26(5):516-22.

21. Hosono H, Kumondai M, Arai T, Sugimura H, Sasaki T, Hirasawa N, Hiratsuka M. CYP2A6 genetic polymorphism is associated with decreased susceptibility to squamous cell lung cancer in Japanese smokers. Drug Metab Pharmacokinet. 2015;30(4):263-8.

22. Kumondai $M$, Hosono $H$, Orikasa $K$, Arai $Y$, Arai T, Sugimura H, Ozono $S$, Sugiyama T, Takayama T, Sasaki T, Hirasawa N, Hiratsuka M. Genetic polymorphisms of CYP2A6 in a case-control study on bladder cancer in Japanese smokers. Biol Pharm Bull. 2016;39(1):84-9.

23. Song DK, Xing DL, Zhang LR, Li ZX, Liu J, Qiao BP. Association of NAT2, GSTM1, GSTT1, CYP2A6, and CYP2A13 gene polymorphisms with susceptibility and clinicopathologic characteristics of bladder cancer in Central China. Cancer Detect Prev. 2009:32(5-6):416-23.

24. Tan W, Chen GF, Xing DY, Song CY, Kadlubar FF, Lin DX. Frequency of CYP2A6 gene deletion and its relation to risk of lung and esophageal cancer in the Chinese population. Int J Cancer. 2001;95(2):96-101.

25. Topcu Z, Chiba I, Fujieda M, Shibata T, Ariyoshi N, Yamazaki H, Sevgican F, Muthumala M, Kobayashi H, Kamataki T. CYP2A6 gene deletion reduces oral cancer risk in betel quid chewers in Sri Lanka. Carcinogenesis. 2002;23(4):595-8.

26. Tsukino H, Kuroda Y, Nakao H, Imai H, Osada Y, Inatomi H, Kitagawa K, Kawamoto T, Katoh T. Genetic polymorphisms ofCYP2A6 andCYP2E1 with tobacco smoking is not associated with risk of urothelial cancer. Environ Health Prev Med. 2002;7(3):129-31.

27. Tsukino H, Kuroda Y, Qiu D, Nakao H, Imai H, Katoh T. Effects of cytochrome P450 (CYP) 2 A6 gene deletion and CYP2E1 genotypes on gastric adenocarcinoma. Int J Cancer. 2002;100(4):425-8.

\section{Publisher's Note}

Springer Nature remains neutral with regard to jurisdictional claims in published maps and institutional affiliations.

Ready to submit your research? Choose BMC and benefit from:

- fast, convenient online submission

- thorough peer review by experienced researchers in your field

- rapid publication on acceptance

- support for research data, including large and complex data types

- gold Open Access which fosters wider collaboration and increased citations

- maximum visibility for your research: over $100 \mathrm{M}$ website views per year

At $\mathrm{BMC}$, research is always in progress.

Learn more biomedcentral.com/submissions 